\title{
SPECIAL TOPICS IN BIOLOGY: ECOLOGY OF GREATER YELLOWSTONE
}

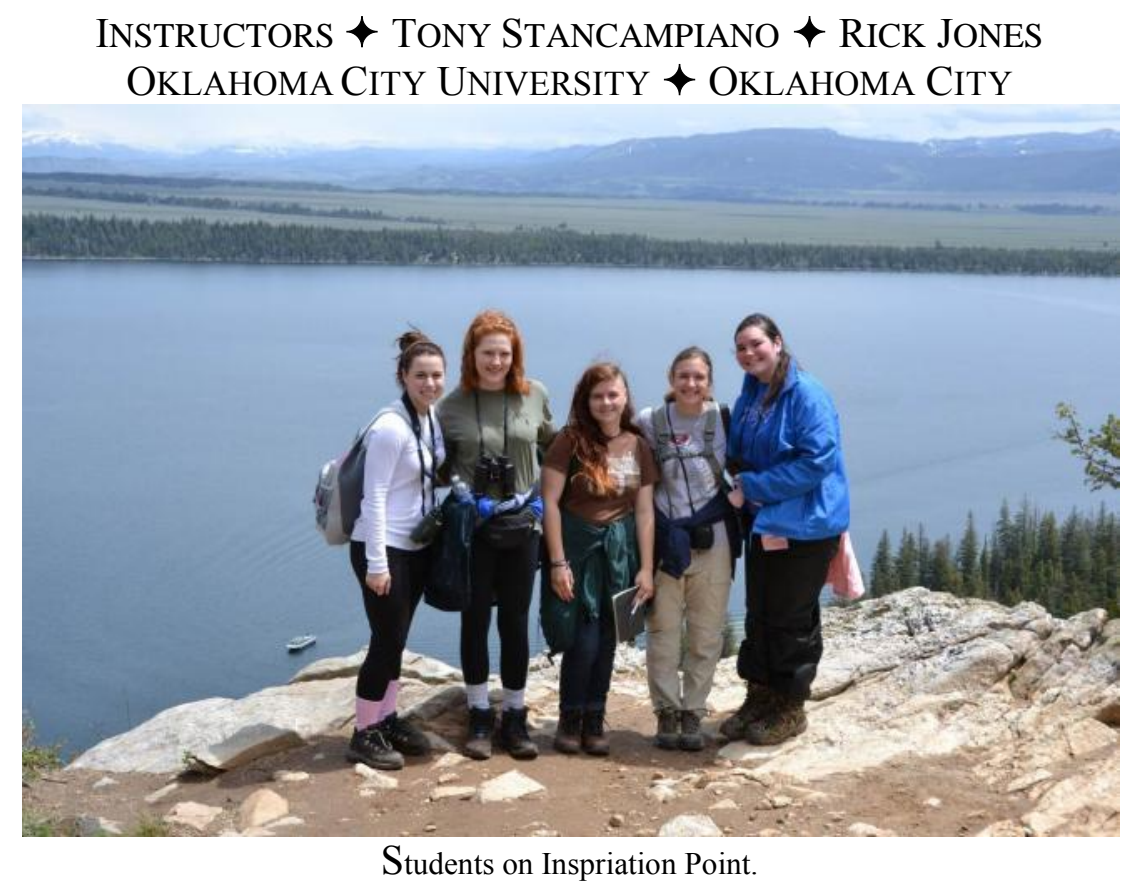

\section{$\uparrow$ Class OVERVIEW}

Special Topics in Biology: Ecology of Greater Yellowstone is a freshman level, non-majors biology course emphasizing basic ecological principles with specific application to the ecosystems found in Grand Teton and Yellowstone National Parks. This course is offered during Maymester at Oklahoma City University. The field portion of the course took place from May 22-31, 2012.

This year 5 students participated in the course. After completing 4 units in the classroom, students embarked on a journey to the AMK Ranch with overnight camping stops in Bayfield, Colorado and Logan, Utah along the way. The 6 day stay at AMK allowed students to experience, in the field, all of the material they had learned in the previous 2 weeks in the on campus portion of the class. The on campus learning consists of a series of lectures and associated exercises providing knowledge from multiple areas including:

- Physical ecology

- Basic geology

- Geology of Yellowstone and Grand Tetons

- Evolution and Natural Selection

- Systematics

- Field identification

- Journaling

We spend each day, while in Wyoming, on a series of hikes in areas that exhibit the features, flora, and fauna discussed in the on campus sessions. Weather permitting, we prefer to split our time between the two parks on an every other day schedule. 
181

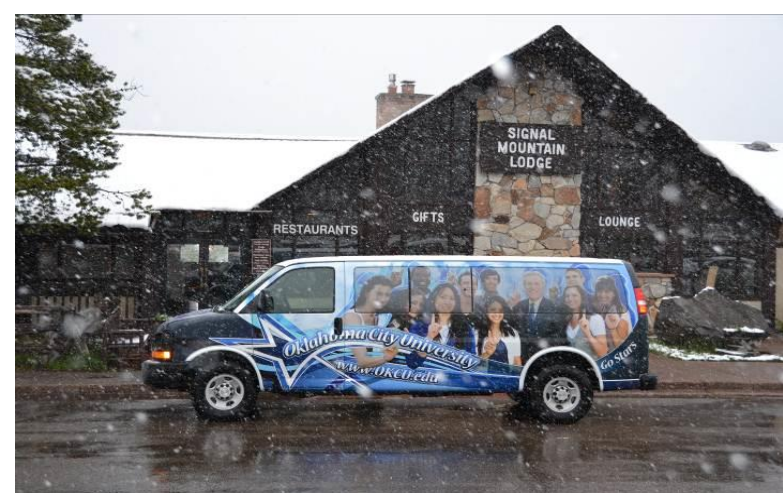

College Van at Signal Mountain Lodge

In terms of logistics, the AMK is ideally located to serve as our headquarters. This setting is truly inspirational to students. The raw beauty of this locale provokes a spiritual feeling and almost palpable calling to investigate. Students learn so much more than the science. Cooperation, tolerance, scheduling, budgeting, history, meal planning and preparation, and consideration of the elements are but a few of the 'extra' skills learned while at the AMK.

Areas visited include, but are not limited to, the following:

- Lewis Falls

- Kepler Cascades

- Lonestar Geyser

- Old Faithful

- Upper Geyser Basin- Firehole River

- Midway Geyser Basin- Grand Prismatic Spring

- Lupine Meadows Trailhead

- LeHardys Rapids

- Hayden Valley

- Grand Canyon of the Yellowstone

- Lamar Valley

- Indian Pond

- Two Ocean Lake

- Miller Butte

- Jenny Lake Area

- Inspiration Point

- Moose Visitor Center and Moose-Wilson

- Road

- Laurence S. Rockefeller Preserve

- Willow Flats

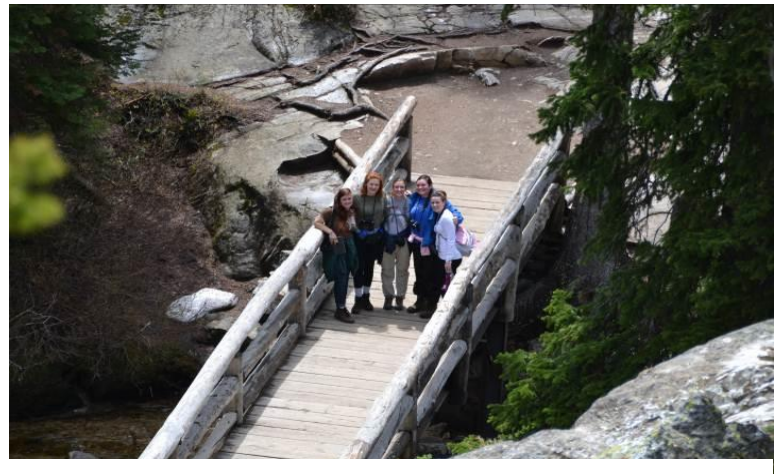

Day Hikes.

The AMK ranch and the University of Wyoming make this unique opportunity possible for

students at OCU. Dr. Henry Harlow and his staff facilitate our housing and accommodations at the AMK. Upon our arrival, Dr. Harlow addresses the students to inform them of general information, current events, personal safety in the parks, bear biology, history of the AMK, and related ecology/biology topics.

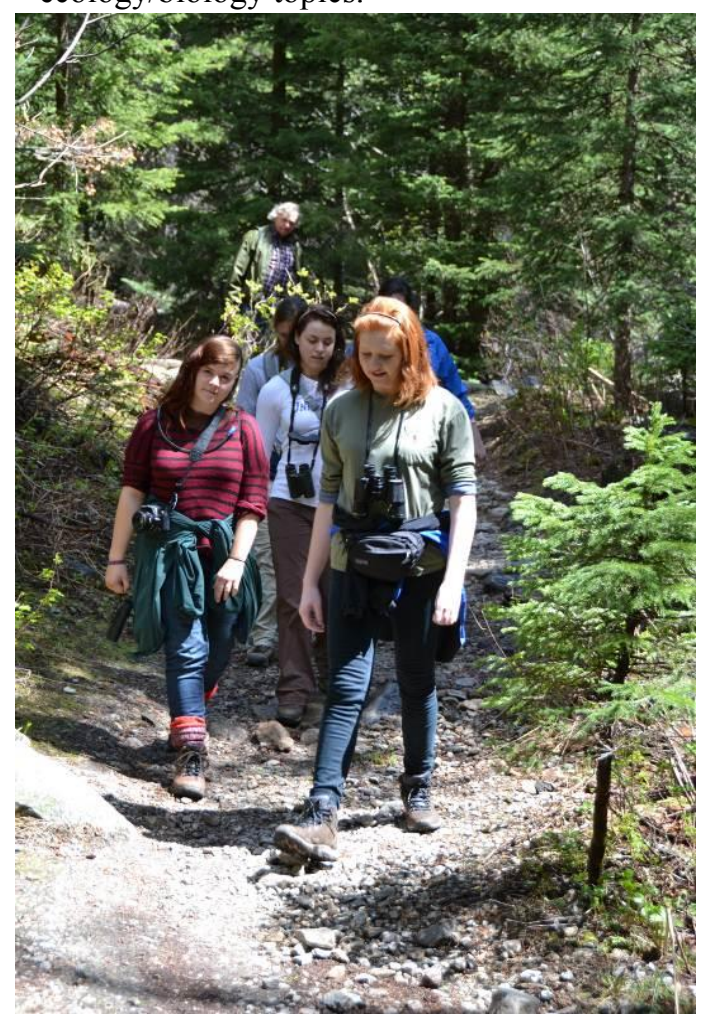

Back Country Tracks. 
182

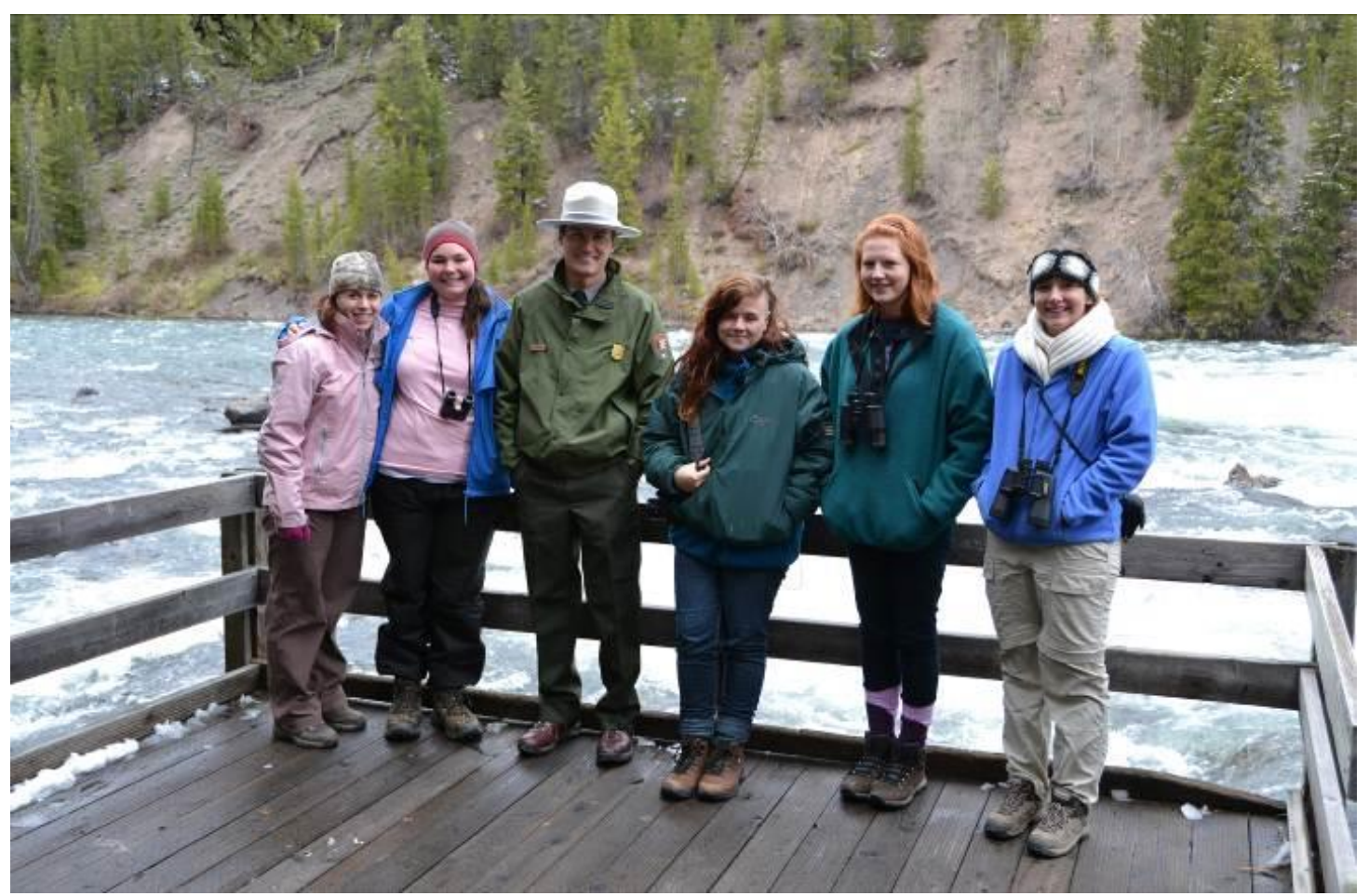

Receiving background information from Park Naturalist 